\title{
Phenolic Content as Antioxidant and Antimicrobial Activities of Pistacia atlantica Desf. (Anacardiaceae) Extract from Libya
}

\author{
Salma O. K. Othman ${ }^{1}$, Maher A.El-Hashash ${ }^{2}$, Sahar A.M. Hussein ${ }^{3 *}$, Amani M.D. \\ El-Mesallamy ${ }^{4}$, Sameh A.Rizk ${ }^{2}$, Fakhri A. Elabbar ${ }^{5}$ \\ ${ }^{1}$ Department of Chemistry, Faculty of Science, Sebha University, Sebha, Libya. \\ ${ }^{2}$ Department of Chemistry, Faculty of Science, Ain-Shams University, Cairo, Egypt. \\ ${ }^{3}$ Department of Phytochemistry and Plant Systematics, National Research Centre, \\ Cairo, Egypt. \\ ${ }^{4}$ Department of Chemistry, Faculty of Science, Zagazig University, Zagazig, Egypt. \\ ${ }^{5}$ Department of Chemistry, Faculty of Science, Benghazi University, Benghazi, Libya.
}

\begin{abstract}
THE AIM of the work is to search for new, potentially biologically active extract.The chemical and biological investigations of different extracts of $P$. atlantica, resulted that the ethyl acetate extract of $P$. atlantica leaves contains a complicated mixture of phenolics, which includes mainly gallotannins as previously detected by 2D paper chromatographic screening. The isolation and identification of six polyphenoles (1-6), were elucidated for the first time from this plant, including three polyphenolic acid; gallic acid (1); ellagic acid (2); 3,3'-dimethoxyellagic acid (3) and three gallotannines, 2,3-di- $O$-galloyl- $(\alpha / \beta)-{ }^{4} \mathrm{C}_{1}$ glucopyranose, nilocitin (4); 1,3 -di- $O$-galloyl- $\beta$-D- $-{ }^{4} \mathrm{C}_{1}$-glucopyranose (5); $1,2,3,4,6$ - penta- $O$ galloyl- $\beta-D-{ }^{4} C_{1}$-glucopyranose (6). The structures of all isolated compounds were elucidated by conventional methods, spectroscopic analysis, including 1D and 2DNMR, ESIMS and HRESI mass as well. The search for new, potentially biologically active extract becomes much more efficient after identification of all compounds in that mixture. The in vitro antioxidant activity using the stable free radical DPPH (2,2-diphenyl-1-pycrylhydrazyl) method of the $P$. atlantica extracts proved that ethyl acetate extract possesses a distinct radical scavenging effect at the different concentrations and the extract completely inhibited DPPH absorbance at a concentration $77 \mu \mathrm{l}$, the percentage of inhibition obtained $96.4 \%$ can be considered as a full absorbance inhibition of DPPH. Also, the $\mathrm{IC}_{50}$ (the concentration that inhibits $50 \%$ of the absorbance of DPPH) of ethyl acetate extract of $P$. atlantica showed an $\mathrm{IC}_{50}$ value of $8.41 \pm 0.24 \mu \mathrm{g} / \mathrm{ml}$ compared with $\mathrm{IC}_{50}$ value of ascorbic acid $1.82 \pm 0.33 \mu \mathrm{g} / \mathrm{ml}$. It could be concluded from the obtained results that the $P$. atlantica ethyl acetate extract shows a very high antioxidant capacity which is very close to the value of the reference standard used, which may be attributed to its high polyphenolic content. P. atlantica extracts demonstrated inhibitory effects against pathogenic microorganisms: Staphylococcus aureus, NCTC 7447; Bacillus subtilis, NCTC 10400; Escherichia coli, NCTC 10416; Pseudomonas aerogenasa NCIB 9016); Candida albicans, IMRU 3669. The active ethyl acetate extract shown a sensitizing effect against Staphylococcus aureus, $20 \mathrm{~mm}$ inhibition zone while the methanolic extract effect against Bacillus Subtilis was $19.5 \mathrm{~mm}$ inhibition zone. The present study has revealed that Pistacia Atlantica Desf. (Anacardiaceae) growing in Libya is capable of synthesizing and accumulating different types of phenolics, including mainly ellagitannins, gallotannins which were elucidated for the first time from this plant. It could be concluded from the obtained results that the $P$. atlantica is a promising source for bioactive compounds which have potential applications as bioactive antioxidant agents for the treatment of diseases.
\end{abstract}

Keywords: Pistacia atlantica Desf. (Anacardiaceae), Phenolics, gallotannines, NMR spectroscopy, Antioxidant DPPH, Antimicrobial activity.

\section{Introduction}

Natural products embrace a wide range of chemical classes among which the class of plant phenols represents the most heterogeneous one, as plant phenols are polyhydroxylated phytochemicals [1]. The phenolic compounds widely distributed in plants are tannins, which may occur as hydrolyzable tannins (formed

\footnotetext{
*Corresponding author e-mail: drsahar90@yahoo.com

DOI: 10.21608/ejchem.2018.4577.1403

C2017 National Information and Documentation Center (NIDOC)
} 
in the pathway of the phenolic acids with sugar polymerization) and condensed tannins (combination of flavonoids). Since polyphenolic compounds are known to exhibit antioxidant properties [2] and can also act as direct scavenger molecules [3], they can prevent lipid peroxidation and biological damage caused by free radicals which formed under oxidative stress.

Pistacia, a genus of flowering plants from the family Anacardiaceae, contains about twenty species, among them five species are more popular including $P$. vera, $P$. atlantica, $P$. terebinthus, $P$. khinjuk, and P. lentiscus [4], that are native to all of Africa, and southern Europe, warm and semi desert areas across Asia. Different parts of these species have been used in traditional medicine for various purposes like tonic, aphrodisiac, antiseptic, antihypertensive and management of dental, gastrointestinal, liver, urinary tract, and respiratory tract disorders. $P$. atlantica is a species of Pistacia tree known by the English common name 'mastic' tree and as the Persian turpentine tree. In Arabic, it is called (Butm or Butum), $P$. atlantica is a deciduous tree growing up to $7 \mathrm{~m}$ $(23 \mathrm{ft})$ tall with branches spreading and growing erect to form a dense crown [5]. Genus Pistacia is characterized by the presence of a wide range of diverse compounds such as flavonoids, triterpenes, sterols and phenolic compounds. The phenolic compounds have been detected in different parts of these species, gallic acid, 3-(8-pentadecenyl)phenol; 3,4,5-tri-O-galloyl quinic acid and 1,2,3,4,6-Pentagalloyl glucose from $P$. vear, P. lentiscus. P. atlantica fruits [6]; and from $P$. lentiscus isolated digallic acid [7]; monogalloyl glucose [8]. The present study aims at the isolation and identification of polyphenols from Pistacia atlantica Desf (Anacardiaceae) leaves as well as evaluation of its biological activities. During the current study, we isolated and identified an additional six phenolic compounds (1-6) from the ethyl acetate extract of $P$. atlantica leaves. All compounds have been characterized for the first time from leaves of Pistacia atlantica.

\section{$\underline{\text { Results and Discussion }}$}

The fresh leaves of dried powdered $P$. atlantica was extracted by successive solvent using Soxhlet extractor, beginning with n-hexane, followed by ethyl acetate and finally with methanol. The received active ethyl acetate extract was subjected to a series of column and preparative paper chromatographic separations to isolate compounds $(\mathbf{1}-\mathbf{6})$. Compounds 4 and 5 have not been described before from this species.

\section{Structure Elucidation}

In this study, the isolation and identification of the major polyphenolic metabolites, particularly phenolic acids and gallotannines of $P$. atlantica were carried out for the first time. Successive column chromatographic separations resulted in isolation of three polyphenolic acids (1-3) which identified as; gallic acid [9]; ellagic acid [10]; 3,3'-dimethoxyellagic acid [11], respectively, on the basis of their chromatographic properties ( $\mathrm{R}_{\mathrm{f}}$-values, fluorescence) under UV-light and their responses towards specific spray reagents for tannins $\left(\mathrm{FeCl}_{3}, \mathrm{KIO}_{3}\right)$. The structures of these three metabolites were confirmed by spectroscopic analysis, including 1D, 2DNMR, and by negative ESIMS, HRESI mass as well. Two new ellagitannins (4,5);2,3-di- $O$-galloyl$(\alpha / \beta)-{ }^{4} \mathrm{C}_{1}$-glucopyranose, nilocitin (4); 1,3-di- $O$ galloyl- $\beta-\mathrm{D}-{ }^{4} \mathrm{C}_{1}$-glucopyranos (5) carried out for the first time from $P$. atlantica and 1,2,3,4,6-penta$O$-galloyl- $\beta$-D- ${ }^{4} \mathrm{C}_{1}$-glucopyranose (6) has been previously isolated from $P$. lentiscus fruits [12].

Compound 4, was obtained as an off-white amorphous powder $(75 \mathrm{mg})$ showed a blue color with $\mathrm{FeCl}_{3}$, and a pink color with $\mathrm{KIO}_{3}$ on $\mathrm{PC}$ indicative of gallotannins. It possessed UV spectral data $\lambda_{\max }: 274 \mathrm{~nm}$. and negative ESIMS spectrum showing $[\mathrm{M}-\mathrm{H}]^{-}$ion peak at $483 \mathrm{mU}$ corresponding to $M r=484$, identical with those reported for digalloyl glucoses. Complete acid hydrolysis of compound 4 , yielded gallic acid and glucose (CoPC, UV spectral data, ${ }^{1} \mathrm{H},{ }^{13} \mathrm{C}$ NMR and ESIMS analysis); On controlled acid hydrolysis 4 yielded an intermediate $\mathbf{4 a}$, which was separated by Prep. PC, using BAW as solvent. 4a was then subjected to chromatographic, UVspectral and negative ESI-MS analysis proving its identity to mono-galloyl glucose (CoPC, UV spectral data, ${ }^{1} \mathrm{H},{ }^{13} \mathrm{C}-\mathrm{NMR}$ and ESIMS analysis). The site of attachment of the two galloyl moieties in the molecule of $\mathbf{4}$ were then determined through ${ }^{1} \mathrm{H}-\mathrm{NMR}$ and ${ }^{13} \mathrm{C}-\mathrm{NMR}$ analysis (DMSO- $d_{6}$, room temperature) the data were in agreement with the achieved structure of $\mathbf{4}$ as 2,3-di-Ogalloyl- $(\alpha / \beta)-{ }^{4} \mathrm{C}_{1}$-glucopyranose or nilocitin [13] (Fig. 1).

Compound 5 was isolated as an off-white amorphous powder $(45 \mathrm{mg})$ showed a blue color with $\mathrm{FeCl}_{3}$, and a pink color with $\mathrm{KIO}_{3}$ on $\mathrm{PC}$ indicative of gallotannins. It possessed $R_{f}$-values, UV spectral data one band at $\lambda_{\max } 278 \mathrm{~nm}$; and negative ESI-MS spectrum showing peak at ([M- 
$\mathrm{H}^{-}$ion at $\mathrm{m} / \mathrm{z}=483 \mathrm{mU}$ corresponding to $M r=484$, to be a digalloyl glucose. Complete acid hydrolysis of compound 5, yielded gallic acid and glucose (CoPC, UV spectral data, ${ }^{1} \mathrm{H}-\mathrm{NMR}$ analysis). The site of attachment of the two galloyl moieties in the molecule of $\mathbf{5}$ were then determined through ${ }^{1} \mathrm{H}-\mathrm{NMR}$ and ${ }^{13} \mathrm{C}$-NMR analysis ESIMS as well as. The ${ }^{1} \mathrm{H}-\mathrm{NMR}$ spectrum of $\mathbf{5}$ revealed two aromatic proton singles, at $\delta 6.98$ and $6.97 \mathrm{ppm}$ assignable to the two existing galloyl moieties. The spectrum also showed in the sugar region, two clearly resolved downfield proton resonances, the most down field of which was found to resonate at $\delta 5.6 \mathrm{ppm}(d, J=8 \mathrm{~Hz})$, attributable to a $\beta$-configurated anomeric glucose proton. The second downfield sugar proton resonance was recognized at $\delta 5.03 \mathrm{ppm}(t, J=8 \mathrm{~Hz})$. The significant downfield shifts, recognized for these two sugar resonance (in comparison with the resonances of the corresponding protons in free $\beta$-glucose) indicated that the hydroxyl groups, geminal to these protons are galloylated, thus proving the structure to be 1,3-di- $O$-galloyl$\beta$-D- ${ }^{4} \mathrm{C}_{1}$ glucopyranose. ${ }^{13} \mathrm{C}-\mathrm{NMR}$ spectrum of
5, exhibited carbon resonances which were in accordance with this structure. The $\beta$-anomeric carbon was recognized from the resonance at $\delta$ $94.1 \mathrm{ppm}$. The most downfield sugar resonance located at $\delta 78.2 \mathrm{ppm}$ is obviously due to the galloylated sugar carbon, C-3. Galloylation at C-3 also followed from the upfield shifts of the resonances of $\mathrm{C}-2$ and $\mathrm{C}-4$, compared to the resonances of the corresponding carbons in the spectrum of free $\beta$-glucose due to $\beta$-effects . The presence of two galloyl moieties in $\mathbf{5}$ follows from the two carboxylic carbonyl carbon resonances, recorded in this spectrum at $\delta 165.4$ and 166.2 ppm. Other chemical shifts of the resonances of the remaining galloyl and glucose carbons in this spectrum were in agreement with the achieved structure of $\mathbf{5}$ as 1,3-di- $O$-galloyl- $\beta-\mathrm{D}-{ }^{4} \mathrm{C}_{1}$ glucopyranose as Fig. 1.

\section{Biological Activities}

Determination of Radical Scavenging activity by DPPH Assay

The evaluation of the antioxidant activity of methanolic and ethyl acetate extracts of $P$.

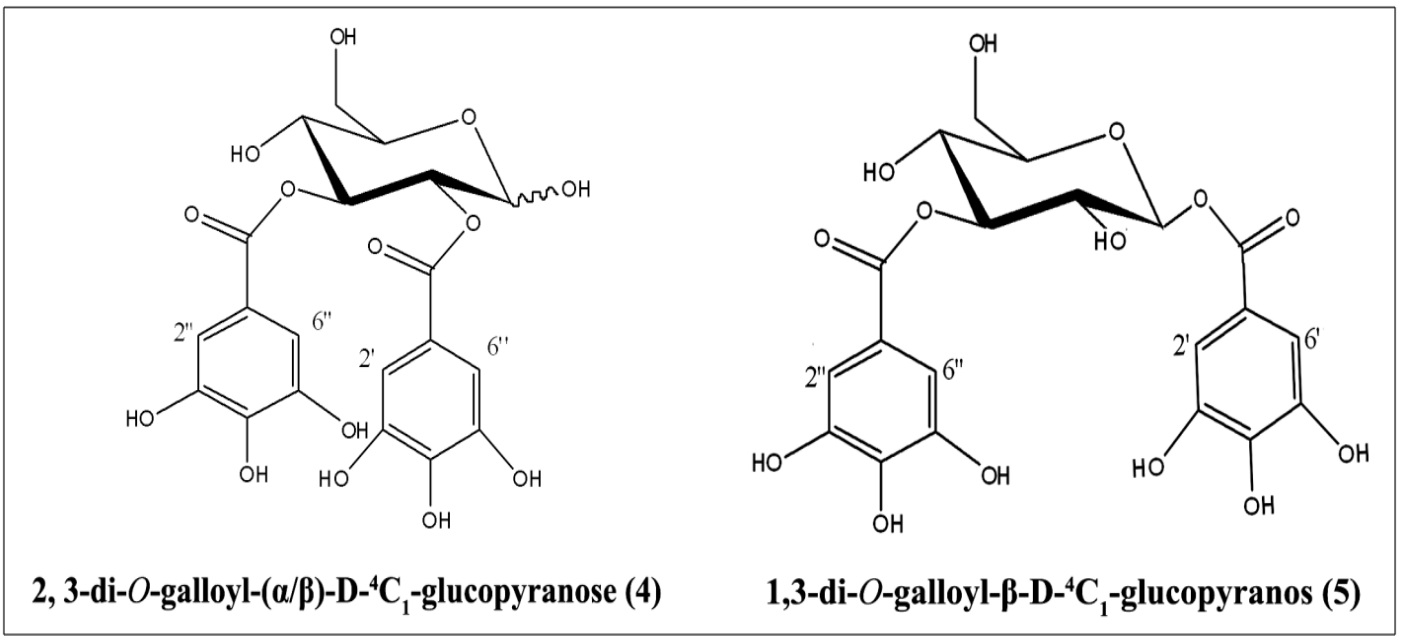

Fig. 1. Chemical structures of compounds (4) and (5).

atlantica were done through in vitro assays by DPPH (2,2-diphenyl-1-pycrylhydrazyl) radical scavenging activity, the extracts of $P$. atlantica showed high values for absorbance inhibition at the 3 different concentrations used, $(19,38,77 \mu \mathrm{l})$ (Fig. 2), ethyl acetate and methanolic extracts possess a distinct radical scavenging effect at concentration $77 \mu \mathrm{l}$, the percentage of inhibition obtained $96.4 \%$ and $53.7 \%$ respectively, the ethyl acetate extract completely inhibited DPPH absorbance which can be considered as a full absorbance inhibition of DPPH. Also, the $\mathrm{IC}_{50}$ (the concentration that inhibits $50 \%$ of the absorbance of DPPH), was determined from the graph plotted for the $\%$ inhibition against concentration in $\mu \mathrm{g} / \mathrm{ml}$ for ascorbic acid and $P$. atlantica ethyl acetate extract which found to be $1.82 \pm 0.33 \mu \mathrm{g} /$ $\mathrm{ml}$ and $8.41 \pm 0.24 \mu \mathrm{g} / \mathrm{ml}$ respectively. It could be concluded from the obtained results that the $P$. atlantica ethyl acetate extract shows a very high antioxidant capacity which is very close to the value of the reference standard used, which may 
be attributed to its high polyphenolic content.

Antimicrobial Activity of Extracts.

Antimicrobial activity of the tested extracts

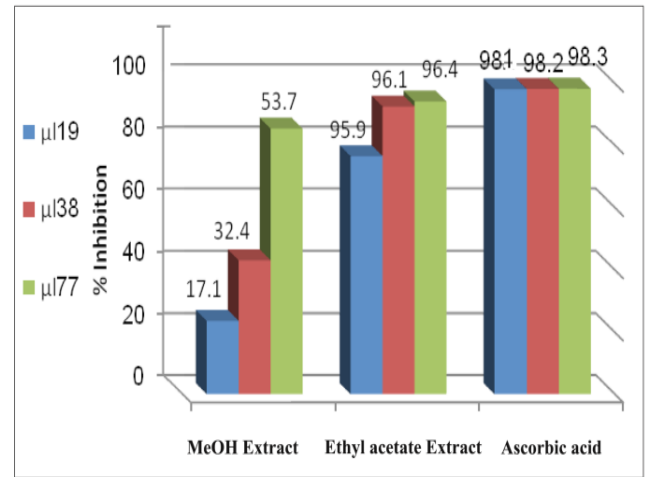

was determined by the agar well diffusion method [14]. In vitro antibacterial activity of the extracts of $P$. atlantica leaves were studied against five

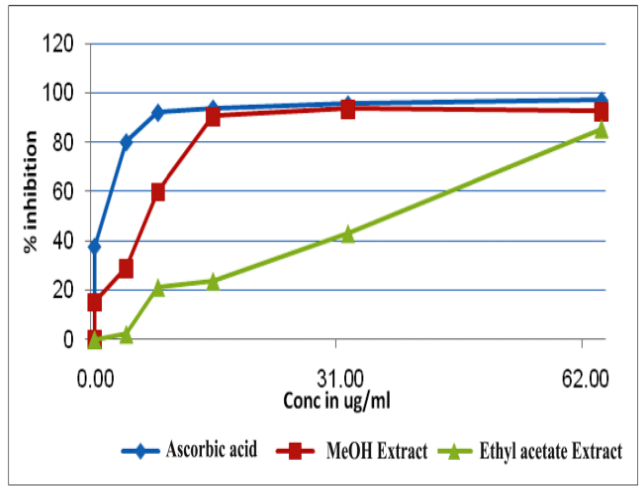

Fig. 2. Antioxidant activity of the two extracts compared to ascorbic acid at $(19,38$ and $77 \mu \mathrm{l})$.

bacteria strain and fungi. The tested organisms were Gram- negative bacteria (Escherichia coli NCTC-10416, Pseudomonas aerogenasa NCIB 9016), Gram-positive bacteria (Bacillus subtilis, NCIB-3610 and Staphylococcus aureus, NCTC7447) and unicellular fungi as (Candida albicans IMRU 3669). The ethyl acetate extract shown a sensitizing effect against Staphylococcus aureus, $20 \mathrm{~mm}$ inhibition zone while the methanolic extract effect against Bacillus Subtilis was $19.5 \mathrm{~mm}$ inhibition zone. The organisms were tested against the activity of $50 \mathrm{mg} / \mathrm{ml}$ of the extract ethyl acetate and methanol results are depicted in the Table1.

TABLE 1. In vitro antibacterial activity of the extracts of $P$. lentiscus and $P$. atlantica.Antibacterial activity of leaves of ethyl acetate and methenolic extracts $(50 \mathrm{mg} / \mathrm{ml})$ of Pistacia atlantica.

\begin{tabular}{lccccc}
$\begin{array}{c}\text { Test } \\
\text { Organisms }\end{array}$ & $\begin{array}{c}\text { Macillus } \\
\text { Subtilis } \\
\text { NCIB-3610 }\end{array}$ & $\begin{array}{c}\text { Escherichia } \\
\text { coli } \\
\text { NCTC- } \\
\mathbf{1 0 4 1 6}\end{array}$ & $\begin{array}{c}\text { Pseudomonas } \\
\text { Aeruginosa } \\
\text { NCIB-9016 }\end{array}$ & $\begin{array}{c}\text { Staphylococcus } \\
\text { Aureus } \\
\text { NCTC-7447 }\end{array}$ & $\begin{array}{c}\text { Candida Albicans } \\
\text { IMRU-3669 }\end{array}$ \\
\hline Eample No. & 17 & 14 & 13 & 16 & - \\
Methyl acetate extract & 19.5 & 13 & 19 & 20 & 18.5 \\
\hline
\end{tabular}

\section{Experimental}

\section{General}

NMR spectra were acquired in DMSO-d on a Jeol ECA $500 \mathrm{MHz}$ NMR spectrometer, ${ }^{1} \mathrm{H}$ at $500 \mathrm{MHz}$ and ${ }^{13} \mathrm{C} 125 \mathrm{MHz}$. Standard pulse sequence and parameters were used to obtain one-dimensional. ${ }^{1} \mathrm{H}$ chemical shifts $(\delta)$ were measured in ppm, relative to TMS, ${ }^{13} \mathrm{C}-\mathrm{NMR}$ chemical shifts to DMSO-d 6 by adding $39.5 \mathrm{ppm}$ and two dimensional COSY, HSQC and HMBC spectra. FTESI-MS spectra were measured on a Finnigan LTQ-FTMS (Thermo Electron, Bremen, Germany) (Department of Chemistry, HumboldtUniversität zu Berlin). UV recording was made on a Shimadzu UV-Visible-1601 spectrophotometer. Paper chromatographic analysis was carried out on Whatman $1 \mathrm{MM}$ and $3 \mathrm{MM}$, using solvent systems: (1) $\mathrm{H}_{2} \mathrm{O}$; (2) $6 \% \mathrm{AcOH}$; (3) $\mathrm{BAW}$ (n-BuOH-AcOH- $\mathrm{H}_{2} \mathrm{O}, 4: 1: 5$, upper layer).

\section{Plant Material}

Fresh leaves of Pistacia atlantica Desf (Anacardiaceae) were collected on May, 2016 from wadi sawfajjin, Beni walid, Libya, the located at 180 kilometers North West of Tripoli. The plant was identified according to Ali, et al. [15]. A flowering voucher specimen is deposited in the herbarium of the Benghazi University, Libya.

Egypt.J.Chem. 62, No.1 (2019) 


\section{Preparation of Extract}

The fresh leaves of dried powdered $P$. atlantica $(2 \mathrm{Kg})$ were extracted by successive solvent extraction using Soxhlet, beginning with n-hexane, followed by ethyl acetate and finally with methanol, (three times extraction, each for $8 \mathrm{~h}$ with 2 L solvent). The three extracts were filtered through filter paper and evaporated to dryness under reduced pressure at $40^{\circ} \mathrm{C}$ in a rotavapor and further used for screening purpose. The dried extracts weights were calculated to give n-hexane (35 g), ethyl acetate (59 g) and methanol (65g), respectively. The three extracts were preliminary investigated for their biological activity.

\section{Isolation and Identification of Phenolics}

The two dimension paper chromatography of the ethyl acetate extract using the solvent systems (1) and (3), respectively, revealed the presence of polyphenolic components. The concentrated ethyl acetate extract (59 g) was chromatographed on a polyamide S6 and repeated Sephadex LH20 column fractionation. The polyamide column $(120 \times 7.5 \mathrm{~cm})$ and eluted with $\mathrm{H}_{2} \mathrm{O}$ followed by $\mathrm{H}_{2} \mathrm{O}-\mathrm{MeOH}$ mixtures of decreasing polarities to yield six subfractions (I-VI ), then started with $\mathrm{H}_{2} \mathrm{O}$ followed by isocratic elution from $10 \%$ to $100 \% \mathrm{H}_{2} \mathrm{O} / \mathrm{MeOH}$. Following removal of the solvents six subfractions were individually collected and subjected to two dimensional paper chromatography (2DPC). Compound 1 (74 $\mathrm{mg}$ ) was isolated pure from $2.50 \mathrm{~g}$ of fraction II. Compounds 2 (48 mg) and $3(86 \mathrm{mg})$ were individually separated purely by fractionation of $2.6 \mathrm{~g}$ of fraction III over Sephadex LH-20 column using a $\mathrm{H}_{2} \mathrm{O} / \mathrm{MeOH}$ mixture of decreasing polarity for elution. Compound 4 (75 $\mathrm{mg}$ ) was individually isolated pure from $2.3 \mathrm{~g}$ of fraction IV by fractionation on a Sephadex LH-20 column and $40 \%$ aqueous $\mathrm{MeOH}$ for elution, followed by preparative paper chromatography (prep. PC), using BAW system for final purification. Compound 5 (45 mg) was individually separated pure from $200 \mathrm{mg}$ of fraction V by (prep. PC), using n-BuOH water saturated as solvent. Compound 6 (38 mg) was isolated pure from $3.5 \mathrm{~g}$ of fraction VI by fractionation on a polyamide column using (methanol: toluene: $\mathrm{H}_{2} \mathrm{O}$ ) (60: 38: 2), followed by preparative PC, using BAW as solvent. Their chemical structure have been established by conventional methods of chemical and physical analysis and confirmed by ${ }^{1} \mathrm{H}$ and ${ }^{13} \mathrm{C}$ NMR spectroscopy.
New compound; 2,3-di-O-galloyl-( $\alpha / \beta)-$ $\mathrm{D}^{-4} \mathrm{C}_{1}$ glucopyranose or nilocitin (4), was obtained as an off-white amorphous powder (75 $\mathrm{mg}$ ) showed a blue color with $\mathrm{FeCl}_{3}$, and a pink color with $\mathrm{KIO}_{3}$ on $\mathrm{PC}$ indicative of gallotannins. $R_{f}$-values: $60\left(\mathrm{H}_{2} \mathrm{O}\right), 65$ (AcOH-6), 50 (BAW), UV spectral data $\lambda_{\text {max }},: 276 \mathrm{~nm}$. it possess negative ESIMS spectrum [M-H] ion peak at $483 \mathrm{mU}$ corresponding to $\mathrm{Mr}=484$, identical with those reported for digalloyl glucoses. Complete acid hydrolysis of compound 4 , yielded gallic acid and glucose (CoPC, UV spectral data, ${ }^{1} \mathrm{H},{ }^{13} \mathrm{C}-\mathrm{NMR}$ analysis); On controlled acid hydrolysis 4 yielded only, one intermediate $\mathbf{4 a}$ which was separated by Prep.PC, using BAW as solvent which proved its identity as a monogalloyl glucose. spectral data of 4:1D- ${ }^{1} \mathrm{H}$ NMR (DMSO- $d_{6}$ ) $\delta$ (ppm): $\alpha$-glucose moiety:5.45 $(1 \mathrm{H}, d, J=3.3 \mathrm{~Hz}, \mathrm{H}-1), 4.92(1 \mathrm{H}$, $d d, J=8 \& 3.3 \mathrm{~Hz}, \mathrm{H}-2), 5.78(1 \mathrm{H}, t, J=8 \mathrm{~Hz}, \mathrm{H}-$ 3),3.1-4.0 ( $m, \mathrm{H}-4,5,6)$; $\beta$-glucose moiety:4.98 $(1 \mathrm{H}, d, J=7.5 \mathrm{~Hz}, \mathrm{H}-1), 5.08(1 \mathrm{H}, t, J=7.5 \mathrm{~Hz}$, $\mathrm{H}-2), 5.41(1 \mathrm{H}, \quad t, J=7.5 \mathrm{~Hz}, \mathrm{H}-3), 3.1-4.0 \quad(m$, $\mathrm{H}-4,5,6)$. Galloyl moieties in $\alpha$ - and $\beta$-anomers $6.87(2 \mathrm{H}, s), \quad 6.81(4 \mathrm{H}, s), \quad 6.79(2 \mathrm{H}, \quad s) .{ }^{13} \mathrm{C}-\mathrm{NMR}$ Spectral Data (DMSO- $\left.d_{6}\right) \delta(\mathrm{ppm})$ : $\alpha$-glucose moiety 89.3 (C-1), 72.2 (C-2), 72.2 (C-3), 68.3 (C-4), 72.2 (C-5), 60.6 (C-6) , $\beta$-glucose moiety 94.5 (C-1), 73.1 (C-2), 75.5 (C-3), 68.3 (C-4), 76.7(C-5), 60.6(C-6). Galloyl moieties in $\alpha$ and $\beta$-anomers; 120.64, 121.38, $121.42\left(\mathrm{C}-1{ }^{\text {' }}\right.$ $\alpha / \beta^{\prime}, 1$ " $\left.\alpha / \beta\right), 109.97(\mathrm{C}-2$ ',6' $\alpha / \beta, 2$ ", 6 " $\alpha / \beta)$, 145.64 (C-3',5' $\left.\alpha / \beta, 33^{\prime \prime}, 5{ }^{\prime \prime} \alpha / \beta\right), \quad 138.67,138.9$ $\left(\mathrm{C}-4{ }^{\prime} \alpha / \beta, 4^{\prime \prime} \alpha / \beta\right), 164.8,165.2,165.4,165.5 \quad(\mathrm{C}=\mathrm{O}$ $\left.\alpha / \beta, C^{\prime}=\mathrm{O} \alpha / \beta\right)$.

New compound; 1,3 -di- $O$-galloyl- $\beta$-D- ${ }^{4} \mathrm{C}_{1}$ glucopyranose (5), was obtained as an off-white amorphous powder $(\mathbf{4 5} \mathbf{~ m g})$ showed a blue color with $\mathrm{FeCl}_{3}$, and a pink color with $\mathrm{KIO}_{3}$ on $\mathrm{PC}$ indicative of gallotannins. $R f$-values: $65\left(\mathrm{H}_{2} \mathrm{O}\right)$, $73(\mathrm{AcOH}), 38$ (BAW); UV spectral data one band at $\lambda_{\max }$ in $\mathrm{MeOH}: 278 \mathrm{~nm}$. Negative ESIMS spectrum showing peak at $[\mathrm{M}-\mathrm{H}]^{-}$ion at $\mathrm{m} / \mathrm{z}=$ $483 \mathrm{mU}$ corresponding to $\mathrm{Mr}=484$, to be a digalloyl glucose ion. On complete acid hydrolysis, yielded glucose and gallic acid (CoPC and ${ }^{1} \mathrm{H},{ }^{13} \mathrm{C}-\mathrm{NMR}$ ). 1D- ${ }^{1} \mathrm{H}$ NMR spectrum allowed the definition of the glucose protons as follows:5.6 $(1 \mathrm{H}, d, J=$ $8 \mathrm{~Hz}$, anomeric $\mathrm{H}-1) .5 .03(1 \mathrm{H}, t, J=8 \mathrm{~Hz}, \mathrm{H}-3)$, 3.2-3.7 (sugar protons overlapped with water protons, H-2,4,5,6). Galloyl moiety: 6.97(2H, $s, \mathrm{H}-2$ ' and H-6'), 6.99 (2H, s, H-2" and H-6"). ${ }^{13} \mathrm{C}$-NMR spectral analysis, afforded a spectrum containing double signals for most of the glucose and galloyl carbons. Resonances were assigned by 
comparison with the ${ }^{13} \mathrm{C}$ NMR data, reported for similar galloyl glucoses. Glucose moiety : 94.1(C1), 77.1(C-2), 78.2(C-3), 70.5(C-4), 71.6(C-5), 61.1(C-6), Galloyl moieties:120.3,119(C-1',1"), 110.1 , 110, 109, 108 (C2',6' and C2",6") , 145.8, 145.7 (C3', 5' and C3',5'), 138.7,139.6(C-4',4"'), $165.4,166.2(\mathrm{C}=\mathrm{O})$.

\section{Biological Assavs}

\section{Radical Scavenging Effect}

Radical scavenging activity of plant extract against the stable freeradicalDPPH(2,2-diphenyl-1picrylhydrazyl, Sigma-Aldrich Chemie, Germany) was determined spectrophotometrically. When DPPH reacts with an antioxidant compound, which can donate hydrogen, it is reduced. The changes in color (from deep violet to light yellow) using UV spectral data at $\lambda_{\text {max: }} 517 \mathrm{~nm}$ Estimation was done to the method of Molyneux et al. [16]. Radical scavenging activity of the extract was measured by slightly modified method of BrandWilliams, Cuvelier, and Berset, C. [17]. Where the extract solution was prepared by dissolving $0.025 \mathrm{~g}$ of the dry extract in $10 \mathrm{ml}$ of methanol. The solution of DPPH in methanol $\left(6 \times 10^{-5} \mathrm{M}\right)$ was freshly prepared, before UV measurements. Three $\mathrm{ml}$ of this solution were mixed with 9 different concentrations of the samples. The resulting solutions were kept in the dark for 30 min at room temperature and then the decrease in absorbance was measured. Absorbance of blank sample containing the same amount of methanol and DPPH solution was prepared and measured. The experiment was carried out in triplicate. Radical scavenging activity was calculated by the following formula:

$$
\% \text { Inhibition }=[(\mathrm{AB}-\mathrm{AA}) / \mathrm{AB}] \times 100
$$

where: $\mathrm{AB}$ is the absorbance of blank sample and $\mathrm{AA}$ is the absorbance of the tested samples.

$\mathrm{IC}_{50}$ value: the concentration of the substrate that causes $50 \%$ loss of the DPPH activity (color), were calculated for the standard and the extract from a graph plotted for the $\%$ inhibition against the concentration in $\mu \mathrm{g} / \mathrm{ml}$.

\section{Antimicrobial Activity of Extracts. \\ Test organisms \\ Bacteria \\ i. Gram-positive bacteria: Staphylococcus aureus, NCTC-7447); Bacillus subtilis, NCIB-3610.}

ii. Gram-negative bacteria: Escherichia coli

Egypt.J.Chem. 62, No.1 (2019)
NCTC-10416, Pseudomonas aerogenasa NCIB 9016

\author{
Fungi \\ Unicellular fungi: Candida albicans, IMRU \\ 3669
}

Microbial cultures were grown on nutrient agar and potato dextrose agar for bacteria and fungi respectively and maintained at $4^{\circ} \mathrm{C}$ in a refrigerator for further studies.

\section{Antimicrobial assay}

The methanolic and ethyl acetate extracts leaves of $P$. atlantica were evaluated for antibacterial activity against five bacteria strain and fungi using the agar diffusion technique [18], $1 \mathrm{mg} / \mathrm{ml}$ solution in dimethyl formamid was used. The DMF showed no inhibition zones [19]. The tested organisms were Gram- negative bacteria (Escherichia coli NCTC-10416, Pseudomonas aerogenasa NCIB 9016), Gram-positive bacteria (Bacillus subtilis, NCIB-3610 and Staphylococcus aureus, NCTC-7447) and unicellular fungi as (Candida albicans IMRU 3669). Microbial cultures were grown on nutrient agar and potato dextrose agar for bacteria and fungi respectively and maintained at $4^{\circ} \mathrm{C}$ in a refrigerator for further studies.

\section{Conclusion}

The present study has revealed that Pistacia Atlantica Desf. (Anacardiaceae) growing in Libya is capable of synthesizing and accumulating different types of phenolics, including mainly ellagitannins, gallotannins which were elucidated for the first time from this plant. It adds to the previously characterized isolation of two new compounds 2,3-di- $O$-galloyl- $(\alpha / \beta)-{ }^{4} \mathrm{C}_{1}-$ glucopyranose $\quad 4$; 1,3 -di- $O$-galloyl- $\beta-\mathrm{D}-{ }^{4} \mathrm{C}_{1}$ glucopyranose 5. According to these results, it could be concluded that the $P$. atlantica ethyl acetate extract shows a very high antioxidant capacity which is very close to the value of the reference standard used. In vitro antibacterial activity of the extracts of $P$. atlantica leaves were studied against five bacteria strains and fungi, ethyl acetate extract shown a sensitizing effect against Staphylococcus aureus, $20 \mathrm{~mm}$ inhibition zone while was $19.5 \mathrm{~mm}$ of methanolic extract against Bacillus Subtilis

\section{Acknowledgment}

This research was supported and financed by Department of Chemistry, Faculty of Science, Benghazi University, Libya, through the Ph.D. linkage program between Prof. Dr. Sahar Hussein at NRC, Cairo, Egypt and Benghazi University. 


\section{References}

1. Haslam E., Lilley T. H., Cai Ya, Martin R. and Magnolato D., Traditional Herbal Medicines: The role of polyphenols, Planta Medica; 55(1), 1 (1989).

2. Mishra K., Ojha H., Chaudhury N., Estimation of antiradical properties of antioxidants using DPPH assay: A critical review and results. Food Chemistry 130, 1036-1043 (2012).

3. Bouchet N., Barrier L. and Fauconneau B., Radical scavenging activity and antioxidant properties of tannins from Guiera senegalensis (Combretaceae), Phytotherapie. Res., 12 (3), 159-162 (1998).

4. Alma M.H., Nitz S., Kollmannsberger H., Digrak M., Efe F.T., Yilmaz N., Chemical composition and antimicrobial activity of the essential oils from the gum of Turkish Pistachio (Pistacia vera L.). Journal of Agricultural and Food Chemistry; 52(12), 39113914 (2004).

5. Martinez J. J. I., Impact of a gall-inducing aphid on Pistacia atlantica Desf. Trees. Arthropod-Plant Interactions; 2(3), 147-151 (2008).

6. Abdelwahed A., Bouhlel I., Skandrani I., Study of antimutagenic and antioxidant activities of Gallic acid and 1, 2, 3, 4, 6-pentagalloylglucose from Pistacia lentiscus. Confirmation by microarray expression profiling. Chemico-Biological Interactions. 165(1), 1-13 (2007).

7. Bhouri W., Derbel S., Skandrani I. et al., Study of genotoxic, antigenotoxic and antioxidant activities of the digallic acid isolated from Pistacia lentiscus fruits. Toxicology in Vitro.; 24 (2), 509-515 (2010).

8. Romani A., Pinelli P., Galardi C., Mulinacci N., Tattini M., Identification and quantification of galloyl derivatives, flavonoid glycosides and anthocyanins in leaves of Pistacia lentiscus L. Phytochemical Analysis; 13(2), 79-86 (2002).

9. Nawwar M.A.M., Sahar A. M. Hussein and Merfort I., NMR spectral analysis of polyphenols from Punica granatum, Phytochemistry, 36(3), 793-798 (1994).

10. Sahar A. M. Hussein, Barakat, H.H., Merfort, I. and Nawwar, M.A.M., Tannins from the leaves of Punica granatum, Phytochemistry, 45 (4), 819-823 (1997).
11. Sahar A. M. Hussein, Flavonoid and methoxyellagic acid sodium sulphates from Frankenia laevis L. Die Pharmazie 59 (6), 484-487 (2004).

12. Mei-Hui Lin, Fang-Rong Chang, Mu-Yi Hua, YangChang $\mathrm{Wu}$ and Shih-Tung Liu, Inhibitory Effects of 1,2,3,4,6-Penta-O-Galloyl- $\beta$-D-Glucopyranose on Biofilm Formation by Staphylococcus aureus, Antimicrobial Agents and Chemotherapy, 55(3), 1021-1027 (2011).

13. Nawwar M.A., Souleman A.M., Buddrus J., Bauer H., Linscheid M., Polyphenolic constituents of the flowers of Tamarix nilotica: The structure of nilocitin, a new digalloylglucose. Tetrahedron Letters 25, 49-51(1984).

14. Kumar G., Karthik L., Rao K.V.B., International Journal of Pharmaceutical Sciences and Research; 1(11), 51-58 (2010).

15. Ali Said S., Fernandez C., Greff S., Derridj A., Gauquelin T., Mevy J-P., Interpopulation variability of leaf morpho-anatomical and terpenoid patterns of Pistacia atlantica Desf. growing in Algeria. Flora.; 206(4), 397-405 (2011).

16. Molyneux P., The use of the stable free radical diphenylpicrylhydrazyl (DPPH) for estimating antioxidant activity. Songklanakarin Journal of Science and Technology, 26 (2) , 211-219 (2004).

17. Brand-Williams W., Cuvelier M.-E. and Berset C., Use of a free radical method to evaluate antioxidant activity. LWT-Food Science and Technology, 28(1), 25-30 (1995).

18. Ibrahim H. S., Eldehn W.M., Abdel-Aziz H, H. A., Elaasser M. M. and Abdel-Aziz M. M., Improvement of antibacterial activity of some sulfa drugs through linkage to certain phthalazin-1(2H)one scaffolds. European Journal of Medicinal Chemistry 85, 480-486 (2014).

19. Bauer A. W., Kirby W. M. M., Sherris J. C. and Turck M., Antibiotic susceptibility testing by a standardized single disk method. Am. J. Clin. Pathol. 45, 493-496 (1966).

(Receieved 25/7/2018; accepted 15/8/2018) 


\section{المحتوى البوليفينولى، كمضيادات للأكسدة و الميكروبات النشطه للمستخلص اوراق نبات البطم الاطلسي من الثعائلة (البطمية) الذي ينمو في ليبياً}

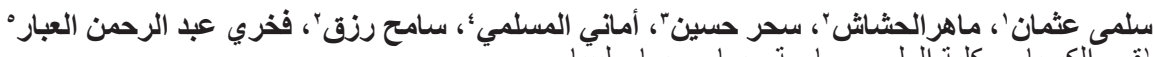

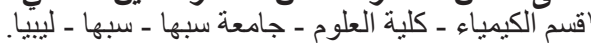

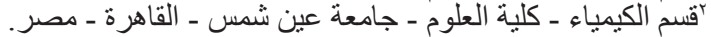

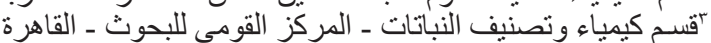

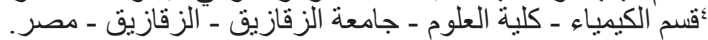

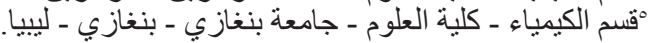

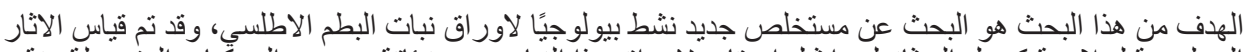
البيولوجية لخلاصنة كحول ألميثانول و ايثيل اسيتات لاور اق هذا النبات و مجزئاتاتة و بعض البطر المركبات المفصنولة منة .

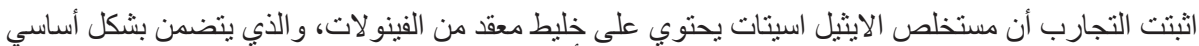

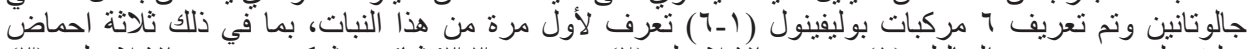

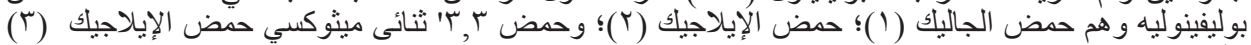
وثثلاث مركبات جلاونانين جديده.

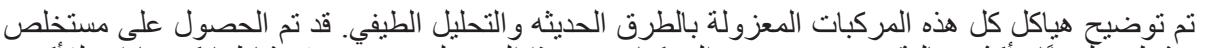

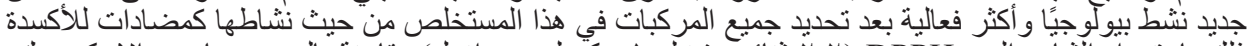

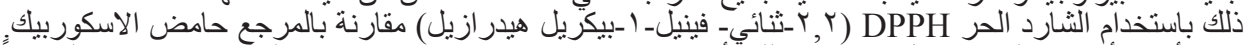

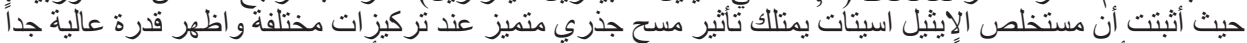

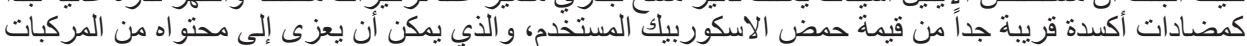
البوليفينوليه العاليه التركيز.

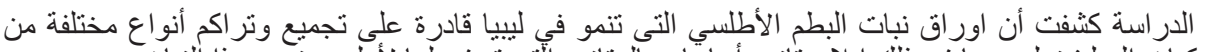

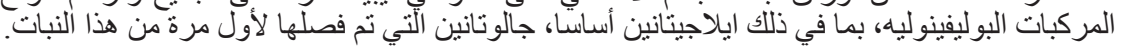

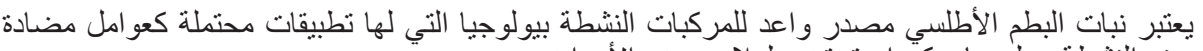

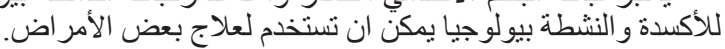

